\title{
Evidências de Doença Tireóidea Auto-Imune Crônica Subclínica em Portadoras da Síndrome de Turner
}

\begin{abstract}
RESUMO
O seguimento de pacientes com síndrome de Turner (ST) freqüentemente revela alterações transitórias, recorrentes e assintomáticas de TSH e/ou hormônios tireóideos (HT). Neste trabalho foram avaliadas estrutura e função da tireóide em portadoras da ST com história de alterações prévias desses hormônios. A casuística incluiu 24 pacientes, 17 com menos de 20 anos, avaliadas laboratorialmente pelas concentrações séricas de TSH, $\mathrm{T}_{4}$ livre, $\mathrm{T}_{3}$ e anticorpos anti-TPO e anti-Tg, e morfologicamente por ultra-sonografia (USG) e cintilografia com pertecnetato$99 \mathrm{~m}$ Tc. Havia alterações de TSH e/ou HT em 13 casos, e em 23 havia alterações USG compatíveis com doença crônica da tireóide, particularmente tireomegalia (estabelecida de acordo com o volume esperado para a estatura) e heterogeneidade do parênquima. A captação foi normal em 21 casos e a distribuição do radiofármaco, homogênea em 22. As alterações hormonais foram independentes da idade, do tempo de evolução, da presença de anticorpos, do número de anomalias USG e de alterações cintilográficas. Pacientes maiores de 20 anos apresentaram maior freqüência de anticorpos e de hipoecogenicidade do parênquima, e houve correlação positiva entre o volume tireóideo e o tempo de evolução, indicando comprometimento progressivo da glândula. Esses resultados sugerem que as alterações encontradas decorram de doença tireóidea auto-imune crônica. (Arq Bras Endocrinol Metab 2007;51/3:401-409)
\end{abstract}

Descritores: Síndrome de Turner; Doença tireóidea auto-imune; Ultra-sonografia; Cintilografia

\begin{abstract}
Evidences for Subclinic Chronic Autoimmune Thyroid Disease in Girls With Turner Syndrome.

Patients with Turner syndrome (TS) frequently exhibit transient, recurrent and asymptomatic variations of TSH and/or thyroid hormones (TH). This work was carried out to evaluate thyroid function and structure in patients with TS who had had such variations in hormone concentrations. Our sample comprised 24 patients, 17 less than 20-years old. Evaluation included serum levels of TSH, free $T_{4}$, total $T_{3}$, TPO and Tg autoantibodies, thyroid ultrasound (US) and scintigraphy with $99 \mathrm{mTC}$ pertechnetate. Thirteen patients had abnormal TSH and/or TH levels; 23 exhibited US features compatible with chronic thyroid disorder, particularly thyromegaly (established according to volume expected for stature) and heterogeneous echogenicity. Uptake was normal in 21 cases and tracer distribution was homogeneous in 22. The finding of abnormal hormone concentrations was independent of age, length of time since the first similar finding, thyroid autoantibodies, number of abnormalities at US and abnormal scintigraphic findings. Patients aged more than 20 years had higher frequency of thyroid antibodies and heterogeneous echogenicity, and thyroid volume was significantly correlated to length of time since detection of the first hormone variation, indicating progressive thyroid disease. These results suggest that subclinical thyroid dysfunction in TS is due to chronic autoimmune thyroid disease. (Arq Bras Endocrinol Metab 2007;51/3:401-409)
\end{abstract}

Keywords: Turner syndrome; Autoimmune thyroid disease; Ultrasonography; Scintigraphy

\section{artigo original}

\author{
Carla C.M. Medeiros \\ SOFIA H.V. DE LEMOS-MARINI \\ MILTON BRÍCOLA FILHO \\ edwaldo E. Camargo \\ allan O. Santos \\ LUIS A. MAGNA \\ GIL GUERRA JÚNIOR \\ MARIA TEREZA M. BAPTISTA \\ ANDRÉa T. MACIEL-GuerRa
}

\author{
Serviço de Endocrinologia \\ Pediátrica, Departamento de \\ Pediatria e Centro de Investi- \\ gação em Pediatria - CIPED \\ (CCMM, SHVL-M, GGJ \& MTMB), \\ Serviço de Ultra-Sonografia, \\ Departamento de Tocogine- \\ cologia (MBF), Serviço de Medi- \\ cina Nuclear, Departamento de \\ Radiologia (EEC \& AOS), e \\ Departamento de Genética \\ Médica (LAM \& ATM-G), Facul- \\ dade de Ciências Médicas - \\ UNICAMP, Campinas, SP.
}

Recebido em 28/09/05

Revisado em 13/04/06 e 08/11/06 Aceito em 10/11/06 
A sinidio. SÍNDROME DE Turner (ST) está presente em 1:2.130 recém-nascidas (1) e caracteriza-se citogeneticamente pela presença de um cromossomo X e perda total ou parcial do segundo cromossomo sexual. O fenótipo é altamente variável; dentre os sinais clínicos, destacam-se baixa estatura e disgenesia gonadal, além de diversos dismorfismos e malformações. São freqüentes, ainda, diversas patologias adquiridas metabólicas, ósseas e auto-imunes, entre as quais destaca-se a doença tireóidea auto-imune (DTAI).

As classificações mais recentes da DTAI incluem, sob essa denominação, a tireoidite auto-imune crônica ou tireoidite de Hashimoto $(\mathrm{TH})$ e suas variantes (como a tireoidite silenciosa), a tireoidite atrófica ou mixedema primário e a doença de Graves (DG) $(2,3)$, uma vez que tudo indica que essas doenças estejam intimamente relacionadas. A DTAI teria, portanto, um amplo espectro, de hipertireoidismo a hipotireoidismo.

A forma mais comum de apresentação da TH na infância e adolescência é a tireomegalia assintomática, embora em alguns casos possa haver manifestações francas de doença tireóidea. O advento de novas gerações de ensaios ultra-sensíveis para determinação da concentração sérica de TSH possibilitou, ainda, o diagnóstico da forma subclínica da tireoidite (4), caracterizada por aumento ou supressão de TSH, concentrações séricas normais de $\mathrm{T}_{4} \mathrm{e} \mathrm{T}_{3}$ (total e livre) e manifestações clínicas ausentes ou escassas (5-7).

A prevalência de hipotireoidismo subclínico na população adulta dos EUA sem doença tireóidea conhecida é de $4 \%$ a $8,5 \%$, e em aproximadamente $75 \%$ dos casos a concentração sérica de TSH está abaixo de $10 \mathrm{mUI} / \mathrm{L}(8,9)$. A incidência de hipotireoidismo franco é de 2,6\% em mulheres com TSH moderadamente aumentado e anticorpos negativos, e de $5 \%$ quando positivos (10).

Os anticorpos antitireóide, antitireoperoxidase (AcTPO) e antitireoglobulina ( $\mathrm{AcTg}$ ) são os mais utilizados para corroborar o diagnóstico da TH (11), e estão presentes em 50 a $80 \%$ dos casos na doença tireóidea auto-imune subclínica (5).

A ultra-sonografia (USG) vem tendo importância destacada no diagnóstico de TH $(12,13)$, uma vez que se trata de método não-invasivo cujos resultados correlacionam-se com a presença de anticorpos e com achados citológicos (14-16) e com maior sensibilidade para detecção de $\mathrm{TH}$ que a presença de anticorpos positivos e alterações nos níveis de TSH (17).

Ao exame por USG, a TH apresenta-se de duas formas: a forma nodular focal, em que se observa nódulo hipoecóico de limites mal definidos, em geral de pequenas dimensões e de difícil diferenciação com nódulos de natureza maligna, e a forma difusa. Nessa última há, numa fase inicial, aumento do volume da tireóide e hipoecogenicidade difusa, com áreas hipoecóicas mal definidas separadas por área de fibrose; ao mapeamento com doppler observa-se hipervascularização do parênquima. $\mathrm{Na}$ fase final, a tireóide evolui com redução do tamanho, contornos mal definidos, textura difusamente heterogênea devido a extensa fibrose e hipovascularização ao doppler (18).

Vários autores consideram que a hipoecogenicidade seja sinal fidedigno de auto-imunidade e indique $o$ grau de comprometimento funcional da glândula, uma vez que estaria associada à intensa infiltração linfocitária que caracteriza a TH $(12,19-21)$ e este sinal já está presente em indivíduos com hipotireoidismo subclínico (22). Deve-se ressaltar, porém, que o padrão de hipoecogenicidade não é específico da TH e pode ser observado também em pacientes com DG ou com tireoidite subaguda (23). Por outro lado, um achado considerado patognomônico de TH à USG é o de heterogeneidade do parênquima (micronodularidade) (24).

Os achados cintilográficos e de captação de pertecnetato-99m Tc ou ${ }^{131}$ I têm papel complementar na diferenciação entre DTAI e outras doenças da tireóide. $\mathrm{Na} \mathrm{TH}$ não há padrão cintilográfico específico, e seus achados devem ser correlacionados ao quadro clínico e laboratorial. Seu papel mais importante é no diagnóstico diferencial em casos de tireotoxicose, uma vez que a captação encontra-se aumentada nos casos de DG isolada ou associada a TH (a chamada hashitoxicose) e diminuída nos casos de tireoidite silenciosa $(25,26)$.

Considera-se, atualmente, que o diagnóstico de TH possa ser feito pelo achado clínico de bócio sem outra causa evidente associado a anticorpos positivos (AcTPO ou AcTg) ou a infiltração linfocítica da glândula. Pode ser suspeitado, porém, em casos de hipotireoidismo primário após serem descartadas outras causas; na presença de anticorpos antitireóideos, mesmo sem disfunção tireóidea ou bócio; em pacientes com neoplasia de tireóide e anticorpos antitireóideos positivos; e em pacientes com hipoecogenicidade e heterogeneidade do parênquima à USG (27).

Vários trabalhos têm comprovado maior freqüência de DTAI na ST em relação à população normal, sendo particularmente freqüente a TH. O hipotireoidismo é a disfunção mais freqüente, encontrada em cerca de $15 \%$ dos casos (28), e sua forma subclínica é bastante freqüente (29); por outro lado, são raros os relatos de hipertireoidismo $(28,29)$.

A prevalência de TH na ST varia de $13,3 \%$ a $55 \%$ de acordo com os critérios utilizados para diagnóstico, a faixa etária abrangida e as técnicas uti- 
lizadas para mensuração dos anticorpos (28-32); na população geral, a prevalência é de $3 \%$ em crianças e adolescentes, $3,38 \%$ a $6,5 \%$ em adultos jovens e acima de $8 \%$ em adultos $(17,33-35)$. Na ST, a TH é rara antes dos três anos de idade e a freqüência aumenta após os 16 anos $(27,36)$. Alguns autores observaram, ainda, maior prevalência nas portadoras de isocromossomo de braço longo do cromossomo X $(4,32)$.

Quanto à apresentação clínica da $\mathrm{TH}$ na ST, tem sido observado que, mesmo nas formas mais graves, e mesmo dentre as pacientes que apresentam anticorpos positivos, a minoria apresenta bócio pela palpação $(33 \%)$ e pela USG $(39 \%)$, indicando que a forma atrófica seja a mais freqüente (36). A freqüência de anticorpos antitireóideos é alta, de $22,2 \%$ a $30 \%$ $(4,28,37,38)$, e a época de detecção é, em média, de 12 a 15,3 anos $(37,39)$.

$\mathrm{Na}$ maioria dos estudos sobre a freqüência de TH na ST, os critérios utilizados foram a presença ou não de disfunção tireóidea franca ou subclínica (hipo ou hipertireoidismo), bócio e anticorpos antitireóide. Dois estudos incluíram como critério diagnóstico os achados de USG (hipoecogenicidade e/ou heterogeneidade). No primeiro, foi realizada USG apenas nas pacientes com anticorpos positivos, e em $10,2 \%$ dos casos os achados foram considerados compatíveis com TH (38). No outro, que considerou somente a hipoecogenicidade como sinal de $\mathrm{TH}$, os resultados diferiram acentuadamente do trabalho anterior, uma vez que esse sinal foi encontrado em praticamente todas as pacientes, independentemente da presença de anticorpos ou de disfunção tireóidea (29).

O seguimento periódico da função tireóidea de pacientes com ST avaliadas em nosso serviço levou à detecção não só de aumento ou supressão de TSH com concentrações séricas normais de $\mathrm{T}_{4}$ (caracterizando hipotireoidismo e hipertireoidismo subclínicos), mas também de outras alterações assintomáticas e transitórias nas concentrações de TSH e $\mathrm{T}_{4}$ de difícil interpretação (40). Considerando que esses achados pudessem ser também decorrentes de processo auto-imune mais amplo, o presente trabalho teve por objetivo realizar avaliação funcional e morfológica da tireóide de pacientes com ST e história de alterações hormonais subclínicas.

\section{CASUÍstica e métodos}

A partir do prontuário de 70 pacientes com ST acompanhadas semestralmente no Serviço de Endocrinologia Pediátrica do Hospital das Clínicas da UNICAMP, com avaliação de TSH ultra-sensível, tiroxina $\left(\mathrm{T}_{4}\right)$ livre e triiodotironina $\left(\mathrm{T}_{3}\right)$ e de anticorpos antitireoperoxidase (AcTPO) e antitireoglobulina (AcTg), foram selecionadas 24 que haviam apresentado, em uma ou mais ocasiões, alterações subclínicas nas concentrações de TSH e/ou hormônios tireóideos (HT) seguidas de eutireoidismo, não sendo necessário instituir tratamento medicamentoso.

Haviam sido observados, em ordem decrescente de freqüência: TSH pouco elevado (entre 4,2 e 10 $\mu \mathrm{UI} / \mathrm{mL}$ ) com HT normais, TSH normal com HT elevados, TSH normal com HT diminuídos, TSH diminuído com HT normais, TSH pouco elevado com HT elevados e TSH diminuído com HT diminuídos. A tabela 1 mostra as características das pacientes que compuseram a amostra e das alterações hormonais prévias encontradas na análise dos respectivos prontuários.

No momento da realização deste trabalho, as idades variavam de 1,6 a 39,2 anos (mediana: 13,7 anos), e a função tireóidea havia sido avaliada em duas a 20 ocasiões, quando dos retornos semestrais. Nenhuma das pacientes havia feito uso de hormônio de crescimento (hGH). Em 11 pacientes, o cariótipo era 45, X (em uma havia, ainda, uma translocação equilibrada entre os cromossomos 2 e 3 ), oito tinham mosaicos sem aberração estrutural $(645, \mathrm{X} / 46, \mathrm{XX}, \mathrm{l}$ $45, \mathrm{X} / 47, \mathrm{XXX}$ e $145, \mathrm{X} / 46, \mathrm{XY})$ e três apresentavam isocromossomo $\mathrm{X}$ (duas em mosaico). Uma paciente apresentava um cromossomo $\mathrm{X}$ e um cromossomo marcador em todas as células analisadas, e outra exibia diferentes aberrações estruturais do cromossomo X em mosaico com linhagem 45 , X.

A idade em que havia sido detectada pela primeira vez, a alteração das concentrações hormonais variou de 1,0 a 37,1 anos (mediana: 9,3 anos); o tempo decorrido desde a deteç̧ão da primeira alteração até a realização deste trabalho (aqui denominado tempo de evolução) variou de 0,1 a 15 anos (mediana: 2,5 anos). Oito pacientes haviam apresentado alterações hormonais em uma única ocasião; nas demais, a recorrência havia sido de até sete ocasiões.

Dentre as 16 pacientes em que as alterações hormonais haviam sido observadas em mais de uma ocasião, nove haviam apresentado diferentes alterações; a combinação mais freqüente foi a de TSH pouco elevado com HT normais e TSH normal com HT elevados. Os anticorpos antitireóide (anti-TPO e/ou Tg) haviam sido detectados em nove pacientes: em quatro, a detecção precedeu a alteração hormonal, em três foi concomitante e em dois foi posterior.

Para a realização do presente trabalho, foram realizadas as seguintes avaliações hormonais: TSH ultra-sensível (faixa de normalidade: 0,35 a 4,2 
Tabela 1. Caracterização de 24 pacientes com síndrome de Turner e das alterações hormonais prévias encontradas na análise dos respectivos prontuários.

\begin{tabular}{|c|c|c|c|c|c|c|c|c|c|}
\hline $\mathbf{N}$ & Cariótipo & $\begin{array}{l}\text { Idade } \\
\text { (anos) }\end{array}$ & $\begin{array}{l}\text { Estatura } \\
\text { (cm) }\end{array}$ & $\begin{array}{l}\text { Primeira } \\
\text { alteração } \\
\text { (anos) }\end{array}$ & $\begin{array}{l}\text { Tempo de } \\
\text { evolução }{ }^{1} \\
\text { (anos) }\end{array}$ & Anticorpos & $\begin{array}{c}\text { Avaliações } \\
\text { funcionais } \\
\text { prévias }\end{array}$ & $\begin{array}{l}\text { Avaliações } \\
\text { com alterações } \\
\text { hormonais }\end{array}$ & $\begin{array}{c}\text { Tipo de alteração hormonal } \\
\text { observada }\end{array}$ \\
\hline 1 & $45, X$ & 1,58 & 78,4 & 1,00 & 0,58 & - & 2 & 2 & $\mathrm{TSH} \uparrow$ e HT nl \\
\hline 2 & $46, X,+$ mar & 5,08 & 95,0 & 4,25 & 0,83 & - & 3 & 3 & $\mathrm{TSH} \uparrow$ e HT nl \\
\hline 3 & $\begin{array}{c}45, X \\
t(2 q-; 3 q+) \text { mat }\end{array}$ & 5,92 & 98,0 & 4,92 & 1,00 & - & 5 & 1 & $\mathrm{TSH} \uparrow$ e HT nl \\
\hline 4 & $45, x$ & 6,08 & 98,1 & 1,58 & 4,50 & $t^{2}$ & 5 & 2 & TSH nl, HT个 \\
\hline 5 & $45, X$ & 6,08 & 95,3 & 3,50 & 2,58 & - & 9 & 4 & TSH $\uparrow$ e HT nl; TSH nl e HT $\uparrow$ \\
\hline 6 & $45, X$ & 7,08 & 108,0 & 4,75 & 2,33 & - & 9 & 3 & $\mathrm{TSH} \uparrow$ e HT nl \\
\hline 7 & $45, X / 46, X X$ & 9,08 & 93,9 & 6,75 & 2,33 & - & 8 & 1 & $\mathrm{TSH} \uparrow$ e HT nl \\
\hline 8 & $45, X / 46, X X$ & 9,75 & 112,4 & 3,83 & 5,92 & - & 7 & 4 & $\begin{array}{c}\text { TSH } \uparrow \text { e HT nl; TSH nl e HT } \downarrow \\
\text { TSH } \downarrow \text { e HT nl }\end{array}$ \\
\hline 9 & $45, X$ & 10,08 & 118,8 & 6,00 & 4,08 & - & 7 & 4 & TSH $\uparrow$ e HT nl; TSH nl e HT $\uparrow$ \\
\hline 10 & $45, X / 46, X X$ & 10,67 & 125,8 & 10,33 & 0,34 & - & 4 & 1 & $\mathrm{TSH} \uparrow \mathrm{e} \mathrm{HT} \uparrow$ \\
\hline 11 & $45, X / 46, X X$ & 10,75 & 134,7 & 5,58 & 5,17 & $t^{3}$ & 9 & 2 & TSH $\uparrow$ e HT nl; TSH $\downarrow$ e HT $\downarrow$ \\
\hline 12 & $45, X$ & 13,42 & 133,6 & 11,75 & 1,67 & - & 4 & 1 & $\mathrm{TSH} \uparrow$ e HT nl \\
\hline 13 & $45, X / 46, X X$ & 13,92 & 143,0 & 13,42 & 0,50 & - & 8 & 1 & $\mathrm{TSH} \uparrow$ e HT nl \\
\hline 14 & $45, X / 47, X X X$ & 15,83 & 152,0 & 15,75 & 0,08 & - & 2 & 1 & $\mathrm{TSH} \uparrow$ e HT nl \\
\hline 15 & $46, X, i(X q)$ & 16,08 & 146,7 & 16,00 & 0,08 & $t^{3}$ & 7 & 1 & $\mathrm{TSH} \uparrow$ e HT nl \\
\hline 16 & $45, X$ & 17,08 & 130,9 & 11,58 & 5,5 & - & 11 & 2 & $\mathrm{TSH} \uparrow$ e HT nl; TSH nl e HT $\uparrow$ \\
\hline 17 & $\begin{array}{c}45, X / 46, X X / \\
46, X, i(X q)\end{array}$ & 18,08 & 141,2 & 8,25 & 9,83 & - & 16 & 3 & 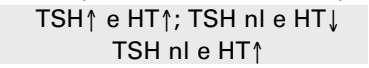 \\
\hline 18 & $45, X / 46, X Y$ & 20,17 & 143,0 & 17,75 & 2,42 & $t^{2}$ & 13 & 1 & $\mathrm{TSH} \uparrow$ e HT nl \\
\hline 19 & $45, X$ & 20,50 & 135,0 & 5,58 & 14,92 & - & 20 & 2 & $\mathrm{TSH}$ ? e HT$\uparrow$ \\
\hline 20 & $\begin{array}{c}45, X / \\
46, X, \operatorname{idic}(X)\end{array}$ & 22,17 & 155,7 & 16,75 & 5,42 & +4 & 9 & 2 & $\mathrm{TSH} \downarrow$ e HT nl \\
\hline 21 & $45, X / 46, X$, del & 22,50 & 135,0 & 20,00 & 2,5 & $t^{3}$ & 8 & 4 & $\mathrm{TSH} \uparrow$ e HT nl \\
\hline 22 & $\begin{array}{c}(X q) / 46, X, r(X) \\
45, X / 46, X X\end{array}$ & 22,58 & 142,5 & 11,42 & 11,16 & $+^{4}$ & 20 & 7 & 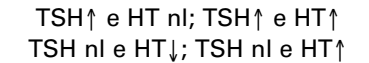 \\
\hline 23 & $45, x$ & 22,58 & 140,0 & 19,67 & 2,91 & $t^{3}$ & 10 & 4 & TSH nl e HT $\uparrow$; TSH $\downarrow$ e HT nl \\
\hline 24 & $45, X$ & 39,17 & 151,0 & 37,08 & 2,09 & $+^{4}$ & 5 & 3 & $\mathrm{TSH} \uparrow$ e HT nl; TSH nl e HT $\uparrow$ \\
\hline
\end{tabular}

$\mathrm{HT}=$ hormônios tireóideos $\left(\mathrm{T}_{4} \mathrm{~L}, \mathrm{~T}_{4} \mathrm{~T}\right.$ e/ou $\left.\mathrm{T}_{3}\right) ; \mathrm{nl}=$ normal; $\uparrow=$ elevado; $\downarrow=$ diminuído

1 Tempo decorrido entre a primeira alteração detectada e a realização deste trabalho; ${ }^{2}$ Positivação posterior à primeira observação de disfunção; ${ }^{3}$ positivação prévia; ${ }^{4}$ positivação concomitante

$\mu \mathrm{UI} / \mathrm{mL}), \mathrm{T}_{4}$ livre $(0,9$ a $1,8 \mathrm{ng} / \mathrm{dL})$ e $\mathrm{T}_{3}$ (recémnascidos: 75 a $260 \mathrm{ng} / \mathrm{dl}, \mathrm{l}$ a 5 anos: 100 a 260 ng/dl, 5 a 10 anos: 94 a $240 \mathrm{ng} / \mathrm{dl},>10$ anos: 75 a $200 \mathrm{ng} / \mathrm{dl}$, adultos: 80 a $200 \mathrm{ng} / \mathrm{dL}$ ), todos avaliados pelo método de quimioluminescência, utilizando analisadores e imunoensaio Elecsys da Roche.

Foram pesquisados os anticorpos AcTPO e AcTg, a mensuração foi feita por técnica de quimioluminescência, utilizando analisadores e imunoensaio Elecsys da Roche, foram considerados positivos valores de AcTPO superiores a $35 \mathrm{UI} / \mathrm{mL}$ e de AcTg superiores a $115 \mathrm{UI} / \mathrm{mL}$.

A tireóide foi, ainda, avaliada por meio de cintilografia e USG. Na cintilografia, a medida da captação foi realizada 20 minutos após a injeção venosa de pertecnetato $-99 \mathrm{~m}_{\mathrm{Tc}}$, sendo considerada normal entre $0,4 \%$ e $1,6 \%$. Esse exame foi realizado no Serviço de Medicina Nuclear do Departamento de Radiologia da FCM - UNICAMP. O preparo das pacientes antes da realização do exame foi feito com orientação dietética e suspensão de medicamentos que pudessem interferir no resultado do exame.
A USG da tireóide foi realizada em todas as pacientes pelo mesmo operador, com aparelho Toshiba Powervision 6000 e sonda linear de alta resolução (8 MHz). O exame foi realizado com o pescoço em hiperextensão, obtendo-se imagens transversais e longitudinais de cada lobo. Foram registrados comprimento, altura e largura para cálculo do volume, e em seguida avaliou-se a regularidade dos contornos, a textura (presença de áreas heterogêneas), a ecogenicidade do parênquima (em comparação com a musculatura adjacente e as glândulas salivares) e a presença de nódulos.

$\mathrm{O}$ volume da tireóide, obtido por meio da USG, foi calculado por meio da fórmula $\mathrm{C} \mathrm{x} \mathrm{L} \mathrm{x} \mathrm{E} \mathrm{x}$ $0,52 \mathrm{em}$ cada lobo, somando-se a seguir o volume dos dois lobos da tireóide $(\mathrm{C}=$ comprimento, $\mathrm{L}=$ largura, $\mathrm{E}=$ espessura); o resultado foi expresso em $\mathrm{mL}$ (41).

Verificou-se, a seguir, que há correlação altamente significativa $(r=0,995)$ entre a média da estatura de meninas brasileiras de 6 a $14 \operatorname{anos}(42,43)$ e a média do volume da tireóide de meninas também brasileiras com as mesmas idades (44). Uma vez que a 
reta de regressão é traçada pela equação $y=-3,931+$ 0,05746.x, é possível obter o volume médio da tireóide (y) esperado para uma menina com determinada estatura (x). Assim, para uma menina de $108 \mathrm{~cm}$ cujo volume observado foi $1,60 \mathrm{~mL}$, o volume médio esperado é $-3,931+0,05746.108$, ou 2,27 mL.

Os limites superior e inferior foram calculados a seguir, multiplicando-se o valor de $t$ para o correspondente grau de liberdade $(\mathrm{t}=2,365 ; \mathrm{gl}=7)$ pelo desvio de regressão $(0,089)$ e aplicando o valor obtido $(0,21)$, para mais ou para menos, em relação ao volume calculado para a respectiva estatura da paciente. No exemplo anterior, o limite inferior é $2,06 \mathrm{~mL}(2,27-0,21)$ e o limite superior, $2,48 \mathrm{~mL}(2,27+0,21)$.

Assim, com base no intervalo de confiança de 95\%, o volume da tireóide de cada paciente pôde ser considerado normal, reduzido ou aumentado a partir do cálculo dos limites inferior e superior para a respectiva estatura, e não para a idade cronológica. A seguir, o volume da tireóide foi ajustado pela média da estatura das pacientes a fim de que essa variável pudesse ser utilizada nas análises estatísticas (teste t e correlação). $\mathrm{O}$ ajuste foi feito somando, ao volume original, o produto da constante 0,05746 pela diferença entre a média da estatura das pacientes que compõem a amostra (que é de 125,3) e a estatura da paciente em questão. Assim, no exemplo anterior o volume ajustado é de $1,60+[0,05746 .(125,3-108)]$, ou 2,59 mL.

A análise dos dados foi feita primeiramente na amostra como um todo, e a seguir as pacientes foram divididas em dois grupos: aquelas na faixa etária pediátrica, até 20 anos de idade $(\mathrm{n}=17)$, e as com idade maior que 20 anos $(n=7)$. Foi feita inicialmente uma análise descritiva, verificando-se, a seguir, a existência de associação entre o achado de alterações nas concentrações de TSH e/ou de HT e a presença de anticorpos (no momento da avaliação ou na história pregressa) e de alterações USG e cintilográficas. As pacientes foram separadas em dois grupos quanto aos achados USG: aquelas com duas ou mais alterações à USG e aquelas com apenas uma característica alterada.

Verificou-se, ainda, se havia diferença significativa entre as pacientes com os diferentes tipos de alteração (hormonal, ultra-sonográfica ou cintilográfica) quanto à idade no momento da avaliação e ao tempo de evolução clínica, e se havia diferença entre as pacientes com e sem alteração hormonal em relação ao volume da tireóide ajustado para a estatura.

A comparação entre proporções foi feita por meio do teste do qui-quadrado ou, quando pertinente, teste exato de Fisher, e a comparação de médias, por meio do teste $t$. Verificou-se, ainda, se havia correlação significativa entre o tempo de evolução clínica e o volume da tireóide ajustado para a estatura.

O estudo foi aprovado pelo Comitê de Ética em Pesquisa da Faculdade de Ciências Médicas da UNICAMP.

\section{RESULTADOS}

Os resultados obtidos encontram-se na tabela 2. As concentrações de TSH e/ou HT mostraram-se alteradas em 13 pacientes, $9 / 17$ na faixa etária pediátrica e 4/7 > 20 anos. Em nove as concentrações de TSH eram moderadamente elevadas (entre 4,2 e 10 $\mu \mathrm{UI} / \mathrm{mL}$ ), oito com HT normais e uma com $\mathrm{T}_{4} \mathrm{~L}$ diminuído; em três pacientes foi iniciado o tratamento com L-tiroxina: aquela com $\mathrm{T}_{4} \mathrm{~L}$ diminuído (de 22,6 anos) e outras duas com sinais clínicos sugestivos de hipotireoidismo (1,6 e 10,7 anos). Em outras quatro pacientes a concentração de TSH foi normal, porém havia alterações nos HT: duas apresentavam concentrações baixas de $\mathrm{T}_{4} \mathrm{~L}$ e elevadas de $\mathrm{T}_{3}$, e em duas apenas as concentrações de $T_{3}$ estavam elevadas.

Os anticorpos foram medidos em 20 pacientes, das quais quatro com resultado positivo, todas com mais de 20 anos e com medidas precedentes positivas. Os anticorpos não foram detectados em três pacientes em que haviam sido previamente positivos.

A avaliação USG revelou alterações de volume da glândula em 23 das 24 pacientes; em 21 havia aumento de volume (observado em todas aquelas $>20$ anos) e redução em duas. A textura apresentou-se heterogênea em 11 pacientes $(6 / 17<20$ anos e $5 / 7>20$ anos), havia irregularidade dos contornos em quatro (três $>20$ anos) e áreas hipoecogênicas em três (todas $>20$ anos). Uma única paciente apresentava nódulo sólido de características USG benignas (nódulo hipercogênico com halo hipoecogênico). Dez apresentavam uma única alteração à USG (alteração de volume), sendo 8/17 pacientes pediátricas e $2 / 7>20$ anos. Em outras dez havia duas alterações, $8 / 17<20$ anos e $2 / 7>20$ anos (de volume e textura em oito, volume e irregularidade de contornos em um, e alteração volumétrica associada a nódulo em um), e em três (todas > 20 anos) havia simultaneamente alterações de volume, textura, ecogenicidade e contornos. Só uma paciente teve USG totalmente normal. Em 10 pacientes, portanto, foi encontrada apenas uma característica alterada à USG e em 13 havia duas ou mais alterações.

A captação de pertecnetato- $99 \mathrm{mTc}$ foi normal em 21 pacientes. Dentre aquelas $>20$ anos, uma teve captação elevada; entre as da faixa pediátrica, uma 
Tabela 2. Resultados da avaliação funcional e morfológica da tireóide de 24 pacientes com síndrome de Turner e história de alterações tireóideas subclínicas.

\begin{tabular}{|c|c|c|c|c|c|c|c|c|}
\hline $\mathbf{N}$ & $\begin{array}{c}\text { TSH } \\
\mathrm{mUI} / \mathrm{mL}^{1}\end{array}$ & $\begin{array}{c}T_{4} L \\
n g / d L^{2}\end{array}$ & $\begin{array}{c}T_{3} \\
\mathrm{ng} / \mathrm{dL}^{3}\end{array}$ & Acs & $\begin{array}{c}\text { Volume } \\
\text { observado } \\
\text { (mL) }\end{array}$ & $\begin{array}{c}\text { Limites } \\
\text { esperados } \\
\text { (mL) }\end{array}$ & $\begin{array}{c}\text { Outras alterações } \\
\text { observadas }\end{array}$ & $\begin{array}{c}\text { Captação de } \\
\text { pertecnetato- } \\
99 \mathrm{mTc}\end{array}$ \\
\hline 1 & $6,26^{*}$ & 1,13 & 227 & - & 0,96 & $0,36-0,78$ & $\mathrm{Cl}$ & $0,36 \%$ \\
\hline 2 & 4,98 & 1,31 & 170 & - & 3,16 & $1,32-1,74$ & & $0,49 \%^{6}$ \\
\hline 3 & 2,57 & 1,55 & NR & - & 2,24 & $1,49-1,91$ & & $\uparrow$ \\
\hline 4 & 2,64 & 1,34 & 205 & - & 3,06 & $1,50-1,92$ & THet & $1,4 \%$ \\
\hline 5 & 3,80 & 1,34 & 168 & - & 2,13 & $1,33-1,75$ & & $0,8 \%$ \\
\hline 6 & 4,73 & 1,24 & 207 & - & 1,60 & $2,06-2,48$ & & $0,75 \%$ \\
\hline 7 & 4,90 & 1,40 & 221 & - & 3,73 & $1,25-1,67$ & & $0,99 \%$ \\
\hline 8 & 3,99 & 1,24 & 178 & - & 2,71 & $2,32-2,74$ & & $1,3 \%$ \\
\hline 9 & 3,88 & 1,37 & 161 & - & 4,80 & $2,69-3,11$ & THet & $0,95 \%$ \\
\hline 10 & $4,85^{*}$ & 1,41 & 172 & NR & 4,10 & $3,09-3,51$ & & $0,66 \%$ \\
\hline 11 & 1,50 & 1,3 & 162 & - & 6,39 & $3,60-4,02$ & & $0,69 \%$ \\
\hline 12 & 4,29 & 1,36 & 111 & NR & 5,71 & $3,54-3,96$ & THet & \\
\hline 13 & 3,46 & 1,07 & NR & - & 2,68 & $4,08-4,50$ & THet & $0,47 \%$ \\
\hline 14 & 6,02 & 1,15 & 155 & - & 9,75 & $4,59-5,01$ & THet & $1,1 \%$ \\
\hline 15 & 2,87 & NR & NR & NR & 5,70 & $4,29-4,71$ & & \\
\hline 16 & 3,24 & 1,18 & 249 & - & 6,36 & $3,38-3,80$ & THet & $0,9 \%$ \\
\hline 17 & 2,43 & 0,85 & 241 & - & 5,07 & $3,97-4,39$ & Nódulo & $1,5 \%$ \\
\hline 18 & 3,24 & 1,18 & 220 & - & 5,62 & $4,08-4,50$ & THet & $2,9 \%$ \\
\hline 19 & 4,30 & 1,30 & NR & - & 9,69 & $3,62-4,04$ & & $1,2 \%$ \\
\hline 20 & 4,03 & 1,13 & NR & NR & 7,15 & $4,81-5,23$ & THet $\mathrm{Cl} \mathrm{AH}$ & $1,6 \%$ \\
\hline 21 & 2,78 & 0,83 & 226 & +4 & 4,74 & $3,62-4,04$ & & $0,76 \%$ \\
\hline 22 & $6,42^{*}$ & 0,89 & 174 & $+4,5$ & 7,03 & $4,05-4,47$ & THet $\mathrm{Cl} \mathrm{AH}$ & $0,5 \%$ \\
\hline 23 & 1,73 & 1,21 & 173 & $+^{4}$ & 6,89 & $3,90-4,32$ & THet & $1,1 \%$ \\
\hline 24 & 3,70 & 0,9 & 115 & $+4,5$ & 7,18 & $4,54-4,96$ & THet $\mathrm{Cl} \mathrm{AH}$ & $0,43 \% 6$ \\
\hline \multicolumn{9}{|c|}{$\begin{array}{l}\text { * Introduzido tratamento de reposição com L-tiroxina. Acs= anticorpos; } \mathrm{AH}=\text { áreas hipoecogênicas; } \mathrm{Cl}=\mathrm{con} \text { - } \\
\text { tornos irregulares; NR= não realizado; THet= textura heterogênea. } \\
\text { Valores normais de TSH: (faixa de normalidade: } 0,35 \text { a } 4,2 \mu \mathrm{Ul} / \mathrm{mL} \text { ); }{ }^{2} \text { Valores normais de T4 livre: }(0,9 \text { a } 1,8) \text {; } \\
\text { Valores normais de T3: recém-nascidos: } 75 \text { a } 260 \mathrm{ng} / \mathrm{dl} ; 1 \text { a } 5 \text { anos: } 100 \text { a } 260 \mathrm{ng} / \mathrm{dl} ; 5 \text { a } 10 \text { anos: } 94 \text { a } 240 \\
\text { ng/dl; > } 10 \text { anos: } 75 \text { a } 200 \mathrm{ng} / \mathrm{dl} \text {; adultos: } 80 \text { a } 200 \mathrm{ng} / \mathrm{dL} ;{ }^{4} \text { Anti-TPO; }{ }^{5} \text { Anti-Tg; }{ }^{6} \text { Distribuição heterogênea do }\end{array}$} \\
\hline
\end{tabular}

apresentou redução e, em outra, a tireóide foi descrita como discretamente hipercaptante (valor da captação não calculado por problemas técnicos). Em duas pacientes com captação normal havia distribuição heterogênea do radiofármaco. A paciente com captação diminuída apresentava TSH elevado e HT normais, porém sinais clínicos de hipotireoidismo que indicaram terapia com L-tiroxina.

O achado de alterações nas concentrações de TSH e/ou de HT nas 13 pacientes não estava associado à detecção, naquele momento ou pregressa, de anticorpos antitireóide $\left(\chi^{2}=2,517 ; \mathrm{gl}=1 ; \mathrm{p}=0,113\right)$, ao número de alterações ultra-sonográficas $\left(\chi^{2}=0,087 ; \mathrm{gl}=\right.$ $\mathrm{l} ; \mathrm{p}=0,768$ ), nem ao achado de alguma alteração (de captação ou de distribuição do radiofármaco) à cintilografia $\left(\chi^{2}=0,087 ; \mathrm{gl}=1 ; \mathrm{p}=0,769\right)$.

Não houve diferença significativa entre as pacientes com e sem alterações nas concentrações de TSH e/ou de HT com relação à idade no momento da avaliação $(\mathrm{p}=0,852)$, ao tempo de evolução clínica $(\mathrm{p}=0,494)$ e ao volume ajustado da tireóide $(\mathrm{p}=0,290)$. A idade e o tempo de evolução também não diferiram quando foram comparadas as pacientes com uma única alteração USG e aquelas com duas ou mais alterações ( $\mathrm{p}=0,105$ e 0,673 , respectivamente), e também quando comparadas aquelas com e sem alterações ao exame de cintilografia $(\mathrm{p}=0,990$ e 0,122 , respectivamente). Observou-se, porém, correlação significativa entre o volume da tireóide ajustado para a estatura e o tempo de evolução clínica $(r=0,463 ; \mathrm{p}=$ 0,023 ), enquanto que a correlação entre o volume e a idade quando da realização deste trabalho foi próxima da significância $(r=0,397 ; p=0,055)$.

As pacientes na faixa etária pediátrica não diferiram daquelas $>20$ anos em relação ao achado de alterações nas concentrações de TSH e/ou $\mathrm{T}_{4} \mathrm{~L}\left(\chi^{2}=\right.$ $0,035 ; \mathrm{gl}=1 ; \mathrm{p}=0,851)$ nem ao número de alterações USG $\left(\chi^{2}=0,910 ; \mathrm{gl}=1 ; \mathrm{p}=0,340\right)$, porém a freqüência de anticorpos entre as mais velhas foi significativamente maior (teste exato de Fisher: $\mathrm{p}=0,03$ ). Quanto ao tipo de achado USG, as pacientes nas duas faixas etárias não diferiram quanto ao achado de heterogeneidade do parênquima $\left(\chi^{2}=2,246 ; \mathrm{gl}=1 ; \mathrm{p}=\right.$ $0,134)$, porém aquelas $>20$ anos apresentaram hipoecogenicidade em freqüência significativamente maior (teste exato de Fisher: $p=0,02$ ). 


\section{DISCUSSĀO}

A história de uma ou mais alterações nas concentrações de TSH e/ou HT em pacientes com ST implica em chance elevada $(>50 \%)$ de que nova alteração hormonal seja detectada. Conseqüentemente, uma vez detectada a alteração, o seguimento clínico e laboratorial deve ser periódico, de modo que as medidas terapêuticas, caso necessárias, sejam prontamente instituídas.

De fato, em três das 13 pacientes (cerca de $1 / 4$ ) a alteração funcional indicou a necessidade de terapia de reposição com L-tiroxina, incluindo uma criança de menos de 2 anos de idade, o que é extremamente raro (36) e reforça a noção de que a TH é não só mais freqüente como de instalação mais precoce na ST que na população geral (28-32). Uma vez que em apenas uma das três pacientes havia anticorpos positivos naquele momento, a periodicidade nas avaliações independe da presença de anticorpos detectáveis. Os anticorpos não se mostraram bons marcadores da TH nas pacientes com ST na faixa etária pediátrica, sendo sua freqüência maior nas pacientes com 20 anos ou mais; esse aumento da presença de anticorpos com a idade é semelhante ao que ocorre na população geral $(17,35)$.

A USG, por sua vez, mostrou-se um exame sensível, corroborando achados da literatura (17). De fato, em quase todas as pacientes havia achados compatíveis com doença tireóidea crônica. A mais freqüente foi a alteração volumétrica, com predomínio acentuado da tireomegalia $(21 / 24)$ sobre a atrofia da tireóide $(2 / 24)$, ao contrário do observado por outros pesquisadores que concluíram ser a atrofia mais comum (38), o que provavelmente se deve à determinação da faixa de normalidade do volume da tireóide com base na estatura da paciente. De fato, o volume tireóideo elevado em paciente com baixa estatura pode ser considerado reduzido se comparado ao de meninas ou mulheres da mesma idade, porém de estatura normal. Além disso, no diagnóstico de bócio pela palpação pode haver variação de até $40 \%$ quando se compara o resultado da avaliação entre diversos examinadores (45).

Em pouco mais da metade dos casos havia mais de uma alteração anatômica detectável à USG, particularmente a heterogeneidade do parênquima, achado freqüentemente associado à TH (24). Diferentemente, porém, do observado por outros autores na ST (29), não foi comum a observação de áreas hipoecogênicas à USG (apenas 3). Isso pode ser devido ao fato de no presente trabalho a amostra não ser aleatória, mas sim constituída por pacientes com história de alterações hormonais subclínicas e, portanto, num estágio provavelmente mais avançado de tireoidite crônica.
A cintilografia mostrou captação normal e distribuição homogênea do radiofármaco na maioria das pacientes, mesmo naquelas com maior número de alterações à USG, indicando, portanto, que seu uso deva ficar restrito ao diagnóstico diferencial de tireotoxicose.

Embora alguns estudos demonstrem que a presença de anticorpos antitireóide aumenta a probabilidade de desenvolvimento de disfunção tireóidea e que alterações à USG correlacionam-se com as concentrações de TSH $(8,46,47)$, neste trabalho o achado de alterações nas concentrações hormonais foi independente não só da presença de anticorpos, mas também do número de alterações da tireóide reveladas pela USG. O encontro de alterações nas concentrações de TSH ou HT também foi independente da idade da paciente e do tempo decorrido desde a primeira alteração detectada (tempo de evolução). Assim sendo, a avaliação periódica da função tireóidea na ST deve ser feita independentemente de todos esses fatores.

A maior freqüência de hipoecogenicidade pela USG nas pacientes $>20$ anos e a correlação positiva entre o volume da tireóide e o tempo de evolução clínica sugerem que há, como seria de se esperar para uma doença crônica, progressão das alterações morfológicas da glândula ao longo do tempo, embora estas nem sempre se acompanhem de alterações funcionais mensuráveis, e estas, quando detectadas, sejam freqüentemente transitórias, entremeadas por períodos de eutireoidismo. O tempo necessário para que a falência da glândula se torne permanente, o que ocorre quando $80 \%$ da tireóide é destruída (48), deve variar na dependência da gravidade do processo que leva ao comprometimento progressivo da glândula e da suscetibilidade individual.

Embora anticorpos antitireóide tenham sido detectados em poucas pacientes, os achados freqüentes de heterogeneidade e/ou hipoecogenicidade do parênquima à USG somam-se aos achados em relação aos anticorpos, contribuindo para reforçar a hipótese de que as alterações funcionais encontradas nessas pacientes sejam decorrentes de $\mathrm{TH}$.

Em mulheres da população geral, o diagnóstico de TH é feito a partir de evidências clínicas de disfunção tireóidea, enquanto que nas pacientes com ST a avaliação funcional é feita periodicamente, independentemente do quadro clínico, permitindo, assim, a detecção de alterações subclínicas. Essas alterações são recorrentes e nem sempre explicáveis no contexto de distúrbios do eixo hipotálamo-hipófise-tireóide. Algumas poderiam ser decorrentes de destruição do parênquima tireóideo, como ocorre na tireoidite silenciosa, 
ou de interferência de anticorpos anti- $\mathrm{T}_{3}$ ou anti- $\mathrm{T}_{4}$ (presentes em 10\% dos indivíduos com doença tireóidea) na mensuração desses hormônios (49).

De todo modo, tudo indica que a causa das alterações variáveis, transitórias e recorrentes nas concentrações de TSH e HT observadas na ST, e muitas vezes iniciadas precocemente na vida dessas pacientes, seja um processo auto-imune crônico e subclínico da tireóide, sendo a USG o método mais sensível para sua deteç̧ão, principalmente na faixa etária pediátrica. Deve-se ter em mente a necessidade de adotar conduta expectante antes de iniciar terapêutica de reposição com L-tiroxina ou com medicamentos anti-tireóideos, repetindo a avaliação hormonal periodicamente e evitando, assim, tratamento desnecessário.

\section{AGRADECIMENTOS}

Os autores agradecem ao Laboratório de Citogenética Humana do Departamento de Genética Médica da Faculdade de Ciências Médicas da UNICAMP e ao Laboratório de Fisiologia do Serviço de Patologia Clínica do Hospital de Clínicas da UNICAMP. Carla Campos Muniz Medeiros recebeu bolsa de doutorado da CAPES durante o desenvolvimento do trabalho.

\section{REFERÊNCIAS}

1. Nielsen J, Wohlert M. Sex chromosome abnormalities found among 34,910 newborn children: results from a 13-year incidence study in Århus, Denmark. Birth Defects Orig Artic Ser 1990;26:209-23.

2. Davies TF, Amino N. A new classification for human autoimmune thyroid disease. Thyroid 1993;3:331-3.

3. Fountoulakis $\mathrm{S}$, Tsatsoulis A. On the pathogenesis of autoimmune thyroid disease: a unifying hypothesis. Clin Endocrinol 2004;60:397-409.

4. Spencer CA, Lopresti JS, Patel A, Guttler RB, Eigen A, Shen $D$, et al. Applications of a new chemiluminometric thyrotropin assay to subnormal measurement. J Clin Endocrinol Metab 1990;70:453-60.

5. Cooper DS. Clinical practice. Subclinical hypothyroidism. $\mathbf{N}$ Engl J Med 2001;345:260-5.

6. Evered D. Subclinical hypothyroidism. In: Ingbar SH, Braverman LE, editores. Werner's The Thyroid: a fundamental and clinical text. $5^{\text {th }}$ ed. Philadelphia: J. B. Lippincott, 1986. pp. 1439-44.

7. Wilson R, Chu CE, Donaldson MD, Thomson JA, McKillop JH, Connor JM. An increased incidence of thyroid antibodies in patients with Turner's syndrome and their first-degree relatives. Autoimmunity 1996;25:47-52.

8. Canaris GJ, Manowitz NR, Mayor G, Ridgway EC. The Colorado thyroid disease prevalence study. Arch Inter Med 2000; $160: 526-34$.

9. Hollowell JG, Staehling NW, Flanders WD, Hannon WH, Gunter EW, Spencer CA, et al. Serum TSH, $\mathrm{T}_{4}$, and thyroid antibodies in the United States population (1988 to 1994): National Health and Nutrition Examination Survey (NHANESIII). J Clin Endocrinol Metab 2002;87:489-99.
10. Toft AD. Clinical practice. Subclinical hyperthyroidism. N Engl J Med 2001;345:512-6.

11. Szeliga DVM, Setian N, Passos L, Lima TMR, Kuperman H, Manna TD, et al. Tireoidite de Hashimoto na infância e na adolescência: estudo retrospectivo de 43 casos. Arq Bras Endocrinol Metab 2002;46:150-4.

12. Raber W, Gessl A, Nowotny P, Vierhapper H. Thyroid ultrasound versus antithyroid peroxidase antibody determination: a cohort study of four hundred fifty-one subjects. Thyroid 2002;12:725-31.

13. Rago T, Chiovato L, Grasso L, Pinchera A, Vitti P. Thyroid ultrasonography as a tool for detecting thyroid autoimmune diseases and predicting thyroid dysfunction in apparently healthy subjects. J Endocrinol Invest 2001;24:763-9.

14. Espinasse $P$, Desuzinges $C$, Cercassi JC. Measurements of an index of echogenicity in some thyroid disease. J Clin Ultrasound 1984; $12: 33-6$.

15. Hayashi N, Tamaki N, Konishi J, Yonekura Y, Senda M, Kasagi K, et al. Sonography of Hashimoto's thyroiditis. J Clin Ultrasound 1986;14:123-6.

16. Ivarsson SA, Ericsson UB, Fredriksson B, Persson PH. Ultrasonic imaging in the differential diagnosis of diffuse thyroid disorders in children. Am J Dis Child 1989;143:1369-72.

17. Kabelitz M, Liesenkötter KP, Stäch B, Willgerodt $H$, Stablein $\mathrm{W}$, Singendonk $\mathrm{W}$, et al. The prevalence of anti-thyroid peroxidase antibodies and autoimmune thyroiditis in children and adolescents in an iodine replete area. Eur J Endocrinol 2003; 148:301-7.

18. Solbiati L, Charboneau JW, James EM, Hay ID. A glândula tireóide. In: Rumack CM, Wilson SR, Charboneau JW (eds). Tratado de ultra-sonografia diagnóstica. Tradução de Idília Ribeiro Vanzellotti, 2a ed. Rio de Janeiro: Guanabara Koogan, 1999. pp. 597-619.

19. Marcocci C, Vitti P, Cetani F, Catalano F, Concetti R, Pinchera A. Thyroid ultrasonography helps to identify patients with diffuse lymphocytic thyroiditis who are prone to develop hypothyroidism. J Clin Endocrinol Metab 1991;72:209-13.

20. Pedersen OM, Aardal NP, Larssen TB, Varhaug JE, Myking O, Vik-Mo H. The value of ultrasonography in predicting autoimmune disease. Thyroid 2000;10:251-9.

21. Sostre $S$, Reyes MM. Sonographic diagnosis and grading of Hashimoto's thyroiditis. J Endocrinol Invest 1991;14:115-21.

22. Loy M, Cianchetti ME, Cardia F, Melis A, Boi F, Mariotti S. Correlation of computerized gray-scale sonographic findings with thyroid function and thyroid autoimmune activity in patients with Hashimoto's thyroiditis. J Clin Ultrasound 2004;32:136-40.

23. Blum M, Passalaqua AM, Sackler JP, Pudlowski R. Thyroid echography of subacute thyroiditis. Radiology 1977; 125:795-8.

24. Yeh HC, Futterweit W, Gilbert P. Micronodulation: ultrasonographic sign of Hashimoto thyroiditis. J Ultrasound Med 1996;15:813-9.

25. Henneman G. Thyrotoxicosis of other etiologies. Disponivel em: <http://www.thyroidmanager.orgs. Acessado em Maio de 2005.

26. Nikolai TF, Brosseau J, Kettrick MA, Roberts R, Beltaos E. Lymphocytic thyroiditis with spontaneously resolving hyperthyroidism (silent thyroiditis). Arch Intern Med 1980;140:478-82.

27. Amino N, de Groot LJ. Hashimoto's Thyroiditis. Disponível em: <http://www.thyroidmanager.org. Acessado em Abril de 2005.

28. Medeiros CCM, Marini SHVL, Baptista MTM, Guerra Jr G, Maciel-Guerra AT. Turner's syndrome and thyroid disease: a transverse study of pediatric patients in Brazil. J Pediatr Endocrinol Metab 2000;13:357-62.

29. Chiovato L, Larizza D, Bendinelli G, Tonacchera M, Marino M, Mammoli $\mathrm{C}$, et al. Autoimmune hypothyroidism and hyperthyroidism in patients with Turner's syndrome. Eur J Endocrinol 1996;134:568-75.

30. Germain EL, Plotnick LP. Age-related anti-thyroid antibodies and thyroid abnormalities in Turner syndrome. Acta Paediatr Scand 1986;75:750-5. 
31. Gruñeiro de Papendieck L, lorcansky S, Coco R, Rivarola MA Bergadá C. High incidence of thyroid disturbances in 49 children with Turner syndrome. J Pediat 1987;111:258-61.

32. de Kerdanet M, Lucas J, Lemee F, Lecornu M. Turner's syndrome with $\mathrm{X}$-isochromosome and Hashimoto's thyroiditis. Clin Endocrinol 1994;41:673-6.

33. Konno N, Yuri K, Taguchi H, Miura K, Taguchi S, Hagiwara K, et al. Screening for thyroid diseases in an iodine sufficient area with sensitive thyrotrophin assays, and serum thyroid autoantibody and urinary iodide determinations. Clin Endocrinol (Oxf) 1993;38:273-81.

34. Prentice LM, Phillips DI, Sarsero D, Beever K, McLachlan SM Smith BR. Geographical distribution of subclinical autoimmune thyroid disease in Britain: a study using highly sensitive direct assays for autoantibodies to thyroglobulin and thyroid peroxidase. Acta Endocrinol (Copenh) 1990,123:493-8.

35. Rallison ML, Dobyns BM, Meikle AW, Bishop M, Lyon JL, Stevens W. Natural history of thyroid abnormalities: prevalence, incidence, and regression of diseases in adolescents and young adults. Am J Med 1991;91:363-70.

36. Lafranchi S. Thyroiditis and acquired hypothyroidism. Pediatr Ann 1992;21:29, 32-9.

37. Chang P, Tsai WY, Hou JW, Hsiao PH, Lee JS. Autoimmune thyroiditis in children with Turner syndrome. J Formos Med Assoc 2000;99:823-6.

38. Radetti G, Mazzanti L, Paganini C, Bernasconi S, Russo G, Rigon $\mathrm{F}$, et al. Frequency, clinical and laboratory features of thyroiditis in girls with Turner's syndrome. The Italian Study Group for Turner's Syndrome. Acta Paediatr 1995;84:909-12.

39. Bright GM, Blizzard RM, Kaiser DL, Clarke WL. Organ-specific autoantibodies in children with common endocrine diseases. J Pediat 1982;100:8-14.

40. Maciel-Guerra AT, Medeiros CCM, Marini SHVL, Baptista MTM, Guerra Jr G. Turner syndrome and thyroid disease: follow-up patients with positive thyroid antibodies. Pediatr Res 2001;49:163A.

41. Brunn J, Block U, Ruf G, Bos I, Kunze WP, Scriba PC. Volumetric analysis of thyroid lobes by real-time ultrasound. Dtsch Med Wochenschr 1981;106:1338-40.

42. Marcondes E, Berquó E, Hegg R, Colli A, Zacchi MAS. Crescimento e desenvolvimento pubertário em crianças e adolescentes brasileiros. I Metodologia. São Paulo: Editora Brasileira de Ciências, 1982.
43. Marques RM, Marcondes E, Berquó E, Prani E, Yunes J. Crescimento e desenvolvimento pubertário em crianças e adolescentes brasileiros. Il. Altura e peso. São Paulo: Editora Brasileira de Ciências, 1982.

44. Rossi A, Tomimori E, Camargo R, Medeiros-Neto G. Determination of thyroid volume by sonography in healthy Brazilian schoolchildren. J Clin Ultrasound 2002;30:226-31.

45. WHO \& ICCIDD. Recommended normative values for thyroid volume in children aged $6-15$ years. World Health Organization \& International Council for Control of lodine Deficiency Disorders. Bull World Health Organ 1997;75:95-7.

46. Hunter I, Greene SA, MacDonald TM, Morris AD. Prevalence and aetiology of hypothyroidism in the young. Arch Dis Child 2000;83:207-10.

47. Schiemann U, Avenhaus W, Konturek JW, Gellner R, Hengst $\mathrm{K}$, Gross M. Relationship of clinical features and laboratory parameters to thyroid echogenicity measured by standardized grey scale ultrasonography in patients with Hashimoto's thyroiditis. Med Sci Monit 2003;9:MT13-7.

48. Scherbaum WA, Miriakian R, Pujol-Borell R, Dean BM, Botazzo GF. Immunohistochemistry in the study and diagnosis of organ-specific autoimmune diseases. In: Polak JM, Van Noorden S (eds). Immunocytochemistry. Modern Methods and Applications. Bristol: John Wright and Sons, 1986. pp. 456-76.

49. Després N, Grant AM. Antibody interference in thyroid assays: a potential for clinical misinformation. Clin Chem 1998; $44: 440-54$

Endereço para correspondência:

Andréa Trevas Maciel-Guerra

Rua Giuseppe Maximo Scolfaro 371, casa 18

13083-100 Campinas, SP

Fax: (19) 3788-8909

E-mail: atmg@fcm.unicamp.br 